neonate who underwent percutaneous insertion of a Vygon central venous catheter after surgery for oesophageal atresia. Injected intravenous contrast material outlines the course of the catheter from posterior auricular vein (PAV) to transverse venous sinus (TVS) via the mastoid emissary vein; contrast also fills the sigmoid venous sinus and internal jugular vein (IJV). Retrograde flow of parenteral feeding solution around a catheter inserted via the posterior auricular vein could therefore reach the transverse venous sinus more directly than the route suggested in the report. Unless the catheter passes directly extracranially to a central vein from this site of entry, which is uncommon, it should be removed. I would endorse previous recommendations that the position of the catheter must always be checked radiographically, ${ }^{34}$ but would not accept a line inserted via the posterior auricular vein that was 'probably in the external jugular vein'. Optimum catheter tip position is in the mid right atrium but parenteral feeding solutions of restricted osmolality can be safely administered for periods of up to 10 days via catheters positioned directly in central great veins (the superior and inferior vena cavae and the internal jugular vein), provided blood can be freely aspirated through the line.

M D STRINGER Department of Paediatric Surgery, Hospital for Sick Children, Great Ormond Street,
London WCIN $3 f H$

1 Rushforth A, Green MA, Levene MI, Puntis $J W L$. Subdural fat effusion complicating parenteral nutrition. Arch Dis Child 1991;66: 1350-1.

2 Williams PL, Warwick R, eds. The veins of the head and neck. Gray's anatomy. 36th Ed. Edinburgh: Churchill Livingstone, 1980: 738-51.

3 Puntis JWL. Percutaneous insertion of central venous feeding catheters. Arch Dis Child 1986; 61:1138-40.

4 Shaw JCL. Technical problems in parenteral nutrition of the premature infant. Acta Chir Scand 1981(suppl):258-66.

5 Stringer MD, Brereton RJ, Wright VMW. Performance of percutaneous silastic central vermance of percutaneous silastic central Pediatr Surgery International 1992;7:79-81.
Complications of splintage in congenital dislocation of the hip

SIR,-May I comment on the recent report by Langkamer, Clarke, and Witherow?' ${ }^{1}$ For many years the great majority of infants in Bristol with congenital dislocation of the hip (CDH) have been managed by the neonatal paediatric staff. With a $\mathrm{CDH}$ incidence of approximately $1.5 \%$ and more than 10000 births each year, it can be estimated that some 1500 infants will have been treated for a few weeks in a light abduction splint (von Rosen or Aberdeen) during the course of a decade. This form of treatment has proved remarkably effective and safe. In a cohort of 445 cases followed up for five years, primary success was achieved in $99 \%$ and there were no cases of avascular necrosis. ${ }^{2}$ The most serious complications were parental anxiety and superficial skin problems. It was thus with concern that I read of the six infants with splintage complications reported by our orthopaedic colleagues, who further stated that 'these cases illustrate that treatment of neonatal hip instability does have a significant complication rate'. ' On this basis they then discussed alternative options to early splintage. Unfortunately no information was given in their report on the population from which their cases were drawn. With their help and permission this crucial data can now be made available. The six infants were born between 1980 and 1987; four were referred into Bristol for treatment of their complications, having been born and splinted elsewhere. Of the two Bristol born infants, one was treated by the paediatric staff while the other was referred at once for orthopaedic care because of a second deformity. (It is of interest that four of the six infants had been treated in a Pavlik harness.) Although incomplete, this information appears to confirm the relative safety of early splintage, in sharp contrast to the high morbidity associated with delayed management. ${ }^{2}$ All the same I wish to support strongly my orthopaedic colleagues' plea regarding the need for expert supervision and regular review of all abduction splintage.

PETER M DUNN Department of Child Health, Southmead Hospital, Southmead Road, Bristol BS10 5NB
1 Langkamer VG, Clarke NMP, Witherow P. Complications of splintage in congenital dislocation of the hip. Arch Dis Child 1991;66: 1322-5.

2 Dunn PM, Evans RE, Thearle MJ, Griffiths HES, Witherow PJ. Congenital dislocation of the hip: early and late diagnosis and management compared. Arch Dis Child 1985;60: 407-14.

\section{Children injured by other children}

SIR,-At child protection conferences perpetrators of injuries to children cannot always be identified. If parents deny responsibility and have no explanations for the injuries the suspicion is that something is being concealed. There is a grave risk of their children entering the care system because the parents are either believed to be the perpetrators or they are deemed to have failed to protect the children.

All workers with children need to be aware of the full range of ways in which injuries occur to children: self injury, injury by parent, by sibling or other children, or by a third party. Some children injure themselves and conceal that they have done so in order to get adults into trouble. ${ }^{1}$

The possibility that one child may injure another, or a sibling injure a sibling, is sometimes too easily dismissed. Research on burned children in the early 1960s showed that nine of 105 children were burned by their siblings or other children-that is, $8 \cdot 6 \%$ of burns in children were child inflicted. ${ }^{2}$

What are the rates of child injured by child for other types of injury that are sometimes unexplained such as bruises, lacerations, fractures, etc?

ROBIN BENIANS 11 Windermere Road, Muswell Hill,

1 Benians R, Goldacre P. Non-accidental injury in children: two cases of concealment of self children: two cases of concea
injury. $B M \mathcal{F} 1984 ; 289: 1583$.

2 Benians R. Psychological aspects of burns in children. Cambridge: Cambridge University 1974. (MD thesis.) 